\title{
BMJ Open PARTNER: a service delivery model to implement optimal primary care management of people with knee osteoarthritis: description of development
}

\author{
Thorlene Egerton (D) , ${ }^{1}$ Rana S Hinman (D) , ${ }^{1}$ David J Hunter (D) ,2,3 \\ Jocelyn L Bowden (D) , 2,3 Philippa J A Nicolson (1) , ${ }^{1,4}$ Lou Atkins (D) , \\ Marie Pirotta (D) , ${ }^{6}$ Kim L Bennell (D) ${ }^{1}$
}

To cite: Egerton T, Hinman RS, Hunter DJ, et al. PARTNER: a service delivery model to implement optimal primary care management of people with knee osteoarthritis: description of development. BMJ Open 2020;10:e040423. doi:10.1136/ bmjopen-2020-040423

- Prepublication history for this paper is available online. To view these files, please visit the journal online (http://dx.doi org/10.1136/bmjopen-2020040423).

Received 13 May 2020 Revised 14 August 2020 Accepted 06 September 2020

Check for updates

(C) Author(s) (or their employer(s)) 2020. Re-use permitted under CC BY-NC. No commercial re-use. See rights and permissions. Published by BMJ.

For numbered affiliations see end of article.

Correspondence to Dr Thorlene Egerton; thor@sutmap.com

\section{ABSTRACT}

Objective Implementation strategies, such as new models of service delivery, are needed to address evidence practice gaps. This paper describes the process of developing and operationalising a new model of service delivery to implement recommended care for people with knee osteoarthritis $(\mathrm{OA})$ in a primary care setting. Methods Three development stages occurred concurrently and iteratively. Each stage considered the healthcare context and was informed by stakeholder input. Stage 1 involved the design of a new model of service delivery (PARTNER). Stage 2 developed a behavioural change intervention targeting general practitioners (GPs) using the behavioural change wheel framework. In stage 3 , the 'Care Support Team' component of the service delivery model was operationalised.

Results The focus of PARTNER is to provide patients with education, exercise and/or weight loss advice, and facilitate effective self-management through behavioural change support. Stage 1 model design: based on clinical practice guidelines, known evidence practice gaps in current care, chronic disease management frameworks, input from stakeholders and the opportunities and constraints afforded by the Australian primary care context, we developed the PARTNER service-delivery model. The key components are: (1) an effective GP consultation and (2) follow-up and ongoing care provided remotely (telephone/email/ online resources) by a 'Care Support Team'. Stage 2 GP behavioural change intervention: a multimodal behavioural change intervention was developed comprising a selfaudit/feedback activity, online professional development and desktop software to provide decision support, patient information resources and a referral mechanism to the 'Care Support Team'. Stage 3 operationalising the 'care support team'-staff recruited and trained in evidence-based knee OA management and behavioural change methodology. Conclusion The PARTNER model is the result of a comprehensive implementation strategy development process using evidence, behavioural change theory and intervention development guidelines. Technologies for scalable delivery were harnessed and new primary evidence was generated as part of the process.
Strengths and limitations of this study

- A systematic development process was undertaken, involving extensive gathering of evidence and using theory and existing frameworks to inform the various development stages and intervention components, and harnessing available technologies.

- Throughout the process, developers were attentive to the local context and stakeholder views.

- A limitation of the development process was the degree of subjectivity that remained, as the members of the development group made decisions based on their own research and clinical practice experiences, beliefs and preconceptions.

Trial registration number ACTRN12617001595303 (UTN U1111-1197-4809)

\section{INTRODUCTION}

Osteoarthritis (OA) is a prevalent chronic joint condition, often resulting in pain, impaired physical function, psychological impairments, lowered quality-of-life and higher healthcare costs. While OA has no cure, there are ways it can be managed to minimise its individual and societal impact. Clinically, OA should be diagnosed based on history and physical examination with imaging investigations generally unnecessary. ${ }^{1-3}$ Holistic assessment of the individual's medical, social and psychological needs enables a tailored approach to treatment formulated in partnership with the patient. Exercise and weight loss are recommended as first-line, core treatments, ${ }^{13-7}$ in addition to education and analgesic/non-steroidal antiinflammatory medication with due consideration of potential harms. ${ }^{467}$ Arthroscopy for knee OA pain is ineffective ${ }^{8}$ and thus 
not recommended, ${ }^{9}$ while joint replacement surgery is advised only when conservative measures fail. ${ }^{10}$

In Australia, general practitioners (GPs) are the first contact practitioners for most people with knee OA. Studies have demonstrated that this primary care is often inconsistent with clinical guideline recommendations. ${ }^{11-13}$ Evidence practice gaps lead to inappropriate care, ${ }^{11} 12$ poorer outcomes ${ }^{14}$ and increased costs to the health system, primarily due to increased disability and surgical rates. The need for effective primary care models was identified as the research priority most likely to alleviate the Australian OA burden by over 50 OA researchers/stakeholders at the 2012 Australian OA Summit. ${ }^{15}$ The need was also recognised in the National Osteoarthritis Strategy following extensive stakeholder consultation. ${ }^{16}$ These and other reports, for example, ${ }^{17}$ highlight the failings of the current system to adequately address the problem and support the need for service redesign. Thus, a new, theory-informed and evidencebased implementation strategy involving a new model of service delivery is needed. The model should be flexible and scalable, able to be integrated into Australian GP practice, allow individualised management-including a comprehensive patient-centred assessment, non-drug, non-surgical treatment options, lifestyle behavioural change and self-management support-and address other health issues that can exacerbate chronic pain. ${ }^{18}$ In this article, we describe the process of developing and operationalising a new model of service delivery to implement recommended care for people with knee OA and fully integrate with existing primary care systems.

\section{METHODS}

The development process is described as three stages. Consistent with the UK Medical Research Council guidance on complex intervention development, these stages occurred concurrently and iteratively. ${ }^{19}$ The article was prepared following the TIDieR and StaRI guidelines as applicable. ${ }^{20} 21$

\section{Stage 1: designing the model of service delivery}

A first step was identifying and prioritising 'optimal care' for people with knee OA. Core components of optimal knee OA care were identified from clinical practice guidelines. Based on a systematic review of clinical guidelines of knee $\mathrm{OA},{ }^{4}$ five guidelines were considered up-to-date at the time (published since 2012) and scored highly in terms of quality ${ }^{22}$ : (1) Osteoarthritis Research Society International (2014), ${ }^{24}$ (2) European League against Rheumatology (2013), (3) American Academy of Orthopaedic Surgeons (2013), ${ }^{9}$ (4) National Institute for Health and Care Excellence (2014) ${ }^{3}$ and (5) American College of Rheumatology (2012) ${ }^{25}$ Recommendations from these guidelines were extracted and pooled to produce a list of recommendations grouped under key clinical areas: Diagnosis, assessment and general management, nondrug conservative interventions, drug recommendations and surgical management. We focused on 'strong recommendations' as determined by the specific rating scale used by the relevant guideline. We also incorporated relevant 'quality indicators'. ${ }^{26-28}$

We also gathered evidence of existing models of $\mathrm{OA}$ care delivery and initiatives from Australia and internationally, plus empirical research on alternative methods of delivering core components of knee OA care. Existing models were identified through literature searching and personal contacts. Several existing national and international models/initiatives were examined ${ }^{429-34}$ from which a set of key features important for optimal delivery, and a set of core principles to underpin care, were produced. With stakeholder input and cognizant of the Australian primary care health setting, we designed the PARTNER model. This aimed to reduce the evidence practice gap in primary care by augmenting existing GP care and integrating a new add-on service that could further address care shortfalls. A theory of the causal links between the features of the new model, effective self-management behaviours and desired patient outcomes was developed to demonstrate the hypothesised capability of the model.

\section{Stage 2: GP behavioural change intervention}

The behavioural change wheel (BCW) methodology ${ }^{3536}$ was used to design an intervention to facilitate practice behavioural changes by GPs in the PARTNER model. The first step was to generate a comprehensive list of ideal GP behaviours. This was narrowed to a shortlist of 'target' behaviours based on: (1) known shortfalls in current GP management, (2) stakeholder opinion on the likely impact of the behaviour, the ease of performing the behaviour, the broader consequences of the behaviour (both positive and negative), and the measurability of the behaviour and (3) the GPs' roles within the PARTNER model. The next step was to develop an in-depth understanding of each target behaviour to help identify what needed to change in order for these behaviours to occur. This was aided by our own qualitative research. ${ }^{37-39}$ Finally, interventions were developed to address as many of the barriers as was feasible and facilitate the desired behaviours.

\section{Stage 3: operationalising the new service}

As part of the PARTNER model, a new service was designed and operationalised with the aim of being feasible, practicable, acceptable, effective and sustainable within the context, while remaining adaptable to individual patient needs and preferences, and new research findings. To do this, we first gathered evidence on barriers and facilitators to the key patient behaviours identified in stage 1 by searching the literature for quantitative and/or qualitative studies on patient experiences, beliefs and preferences related to these identified behaviours. We also conducted informal discussions with patients and experts (unpublished), used our own knowledge and experience of delivering care remotely using technology, ${ }^{40-42}$ and, as much as possible, used and/or modified existing services and 
resources. Finally, we also conducted research to maximise the acceptability and engagement of local GPs. ${ }^{43}$

\section{Patient and public involvement}

The study was supported by a consumer group and other individual consumers who provided input to the design of the new model at several stages. This consumer group and individual consumers were involved in online surveys, a focus group and interviews. Members of a consumer advocacy organisation were also involved at several stages including with the scoping of existing educational materials.

\section{RESULTS}

\section{Stage 1: model design}

Identifying and prioritising optimal care components

Identifying and prioritising core components of optimal knee OA care and quality indicators resulted in 36 practice recommendations that constitute optimal care for people with knee OA. These are provided in online supplemental additional file 1 .

\section{Key features of high-quality services from other models of}

delivering oa care

The scoping exercise on current Australian OA care services found variation across jurisdictions, but most were providing care in tertiary hospital orthopaedic clinics. ${ }^{44}$ Quality improvement projects within local primary care services exist, but in the opinion of the research team are not widely implementable due to their focus on local contextual issues. Important findings from our examination of existing national and international models ${ }^{49-34}$ and published systematic reviews ${ }^{45-47}$ included that patient education, behavioural change support, goal-setting, shared decision making and problem-solving skill-building are all helpful for facilitating effective self-management. A further finding was that lifestyle changes often require support over long periods of time by providers with specialist skills and ideally, expert knowledge of the condition. ${ }^{29} 334546$ Therefore, proactive patient review was considered an important feature to include in a new service. In addition, delivery service design should consider flexible team roles, ${ }^{45-47}$ opportunities for task sharing among staff ${ }^{4547}$ and efficient care coordination. ${ }^{29} 3045-47$

Other features include that treatments, delivery methods and behavioural change interventions used in the service should be evidence based. Clinicians should have high-level communication skills for facilitating health literacy and behavioural change. The service should be cost efficient and be able to attract sustainable long-term funding. Finally, it should be harmonious with the local health service organisation.

\section{Core principles to underpin of the care delivery}

Core principles incorporated into the design included Wagner's theoretical framework for the management of chronic disease, the biopsychosocial model of healthcare and patient-centredness. Wagner's theoretical framework is a well-recognised and accepted model of chronic care. ${ }^{48}$ It is a broad theoretical framework that describes the elements needed to effectively care for people with chronic conditions such as knee OA. The model describes how health systems need to consider the design of service delivery to include self-management support and decision support for patients. The model highlights the importance of patients being informed and 'activated' (a measure of self-management capabilities), and health practitioners being adequately prepared. The service should adopt a biopsychosocial approach, whereby activity and participation are seen as the mechanism for achieving better symptom control. ${ }^{49}$ The service should also be underpinned by patient-centred care principles and thus be responsive to individual needs and preferences and allow flexibility and individualisation of treatment plans.

\section{Methods of delivery}

Various options for delivery of care include primary versus tertiary settings, public and/or private community services, single and multiprofession services (eg, practice nurses, physiotherapists, health coaches) and remote (eg, telephone, web based) versus individual in-person versus group in-person delivery options. Remote models are effective, can improve access to care and can reduce cultural, language, socioeconomic and geographical inequities. ${ }^{50} 51$ A systematic review supports the efficacy of telephone-delivered interventions for improving physical activity levels in people with chronic disease. ${ }^{52} \mathrm{~A}$ recent study showed physiotherapy management of knee OA can be effectively delivered remotely by skype ${ }^{53}$ and via telephone. ${ }^{54}$ Importantly, outcomes are equivalent between remotely and conventionally delivered services, ${ }^{55}{ }^{56}$ but with additional cost saving and time saving benefits. ${ }^{57}$ Other potential advantages of remote-delivery models are their ability to overcome issues of quality control, adapt to future changes in both content and delivery due to the small number of staff involved, being more easily scaled up or down, and having potential to improve equity of service (accessible to remote/rural patients and those with mobility or language barriers). The theoretical technological divide is a potential disadvantage both in terms of availability of equipment (all patients need a telephone at the very least), and the need for patients and providers to engage with a non-traditional form of healthcare delivery.

\section{Stakeholder involvement}

A development group and several working groups of interested stakeholders (including representatives from consumer advocacy organisations, consumers, GPs, physiotherapists, rheumatologists, nurses, behavioural change experts, policy makers and health insurers) informed the service design. We organised several online surveys, meetings and a focus group including patients. ${ }^{58}$ The 
feedback highlighted parts of our planned intervention that were not intuitively beneficial to some and flagged important barriers to acceptance and uptake early in the development process. However, some of the suggestions of lay participants were inappropriate as they were based on inaccurate knowledge of care recommended in highquality clinical practice guidelines.

\section{Understanding the context}

Any implementation strategy is constrained by the local context. ${ }^{19}$ A new model of service delivery needs to be feasible and sustainable within current systems. In Australia, management of knee OA tends mostly to occur in primary care settings, ${ }^{59}$ with $75 \%$ of people with knee OA visiting a GP. ${ }^{60}$ GPs work in a fee for service system within practices that are privately owned and run as small businesses. In Australia, as elsewhere, GPs predominantly practice within a biomedical framework. ${ }^{48}$ Care is less often patient centred and there is less opportunity for facilitating shared decision-making and supporting effective self-management. ${ }^{61}$ GPs experience multilevel barriers to implementing optimal care, ${ }^{62}$ in particular with regard to their confidence and attitudes towards $\mathrm{OA}$ care. ${ }^{63}$ In addition, the rebate structure restricts expansion of their role and limits the duration of consultations. GPs themselves recognise there are system barriers to providing optimal care. ${ }^{3864}$ A report by Arthritis Australia highlighted that GPs describe time constraints and a lack of skill and confidence in behavioural counselling as key factors constraining better OA care. ${ }^{65}$ GPs also feel hampered by lack of access to services that support lifestyle changes. ${ }^{38}{ }^{65}$ In Australia, other primary healthcare professions are often difficult to access due to cost, location or availability. GPs ${ }^{65}$ and others ${ }^{66}$ have called for new models for delivering OA care that allow multidisciplinary input to help support lifestyle change and self-management since the current model of relying predominantly on GPs is failing patients.

The new model to deliver optimal care (the partner model) Since substantial changes to GP practice behaviour, or the health system, were not feasible, it was evident that in order for people with knee OA to receive the care they need, the bulk of care would have to be provided by health professionals other than GPs. Several alternative models were discussed by the development team, including models using community physiotherapists or practice nurses. Both these models were considered to have major practical barriers to implementation and large-scale roll-out. Thus, we decided that a model where care is provided remotely by a small team of highly skilled, multidisciplinary health professionals would be the most practical and sustainable method of delivering optimal care in the Australian healthcare context.

The PARTNER model (figure 1) was proposed as a solution to address the known shortfalls in current knee OA care and deliver optimal care. The proposed model also has the potential to provide continuous, long-term support, empower patients by raising health literacy, and incorporate a range of behavioural change techniques to support long-term effective self-management. It uses remote-delivery options (telephone and internet) to provide ongoing 'care support'. In the proposed model, the GP refers the patient to the 'care support team' (CST) following a brief initial consultation emphasising the importance of exercise, physical activity and weight loss. The healthcare professionals in the CST have skills in communication, patient education and health behavioural change, plus expertise in current best practice for knee OA management.

\section{Theoretical causal pathway}

A proposed theory of the causal pathway between the features of the new model, effective self-management behaviours and desired patient outcomes was developed to demonstrate the hypothesised capability of the model (figure 2).

\section{Stage 2: GP behavioural change intervention}

There are two distinct parts of the PARTNER model implementation strategy: (1) a brief initial consultation with the GP who provides care consistent with guideline recommendations and (2) ongoing care provided by the CST. The model, therefore, requires some degree of

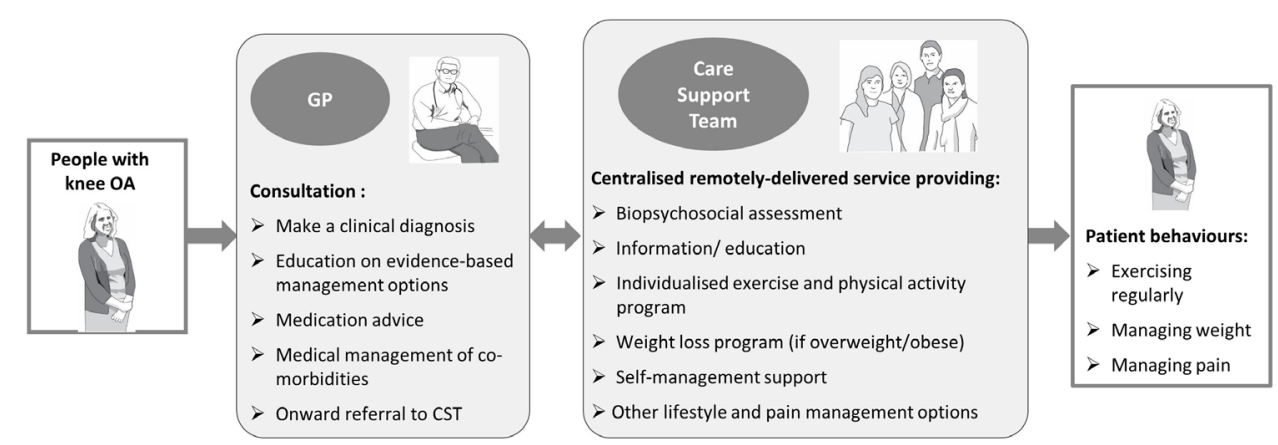

Figure 1 The new implementation strategy: partner model of service delivery. The model includes a focus on core lifestyle interventions (exercise, physical activity, and weight loss, if overweight), incorporating the key features (specialised, evidencebased, sustainable, cost-efficient, flexible and able to be tailored to individual needs and preferences) and the core principles (biopsychosocial approach, patient-centred care) and compatible within the local context. GP, general practitioner; OA, osteoarthritis. 


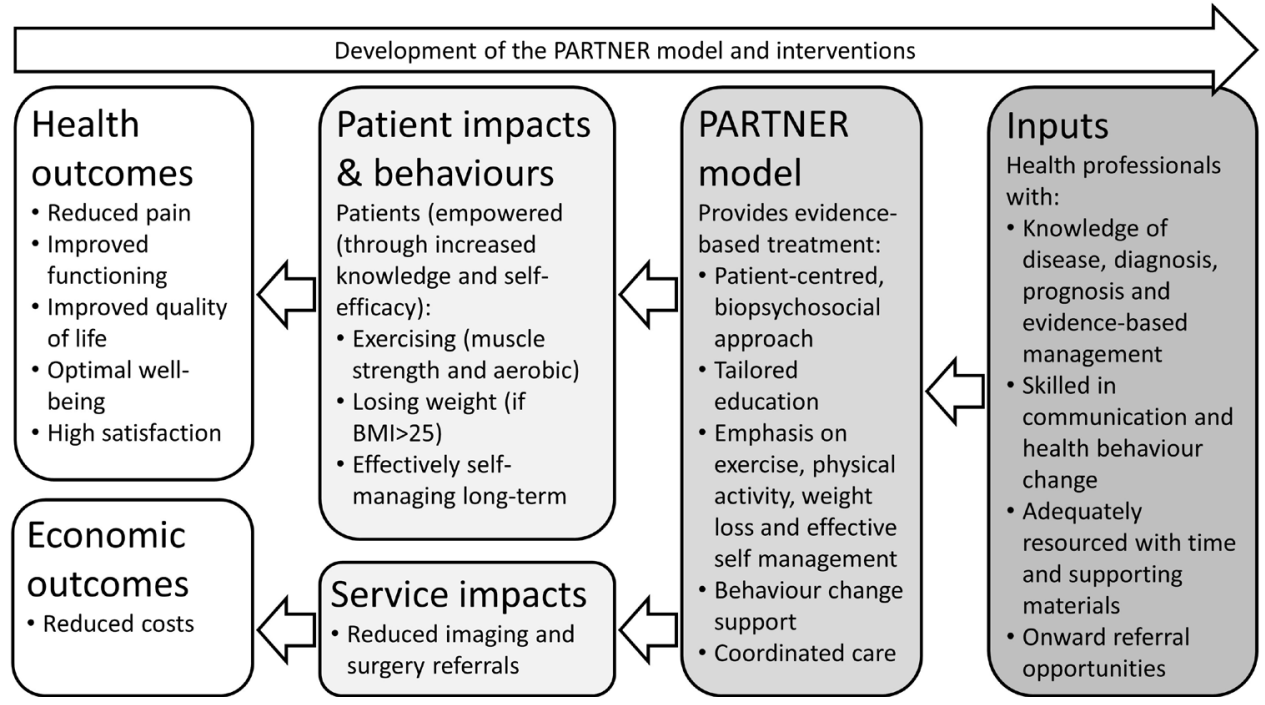

Figure 2 Causal pathway underpinning the partner model. In the pathway, the key 'active ingredients' of the optimal evidencebased intervention for knee OA are patient behaviours including participating in exercise and physical activity, losing weight (if overweight or obese) and effectively self-managing. The 'active ingredients' in the implementation strategy (the partner model), are the roles and behaviours of GPs and the CST. BMI, body mass index; CST, Care Support Team; GP, general practitioner; OA, osteoarthritis.

practice behavioural change by GPs. The $\mathrm{BCW}^{35}$ methodology for developing behavioural change interventions was used to develop an intervention targeting GPs (the PARTNER GP behavioural change intervention). The BCW step 1 is to focus the aims and identify a small number of behaviours to target.

\section{BCW Step 1: clearly describe the problem and what needs to change}

We examined research highlighting evidence-practice gaps in GP management of knee OA with a focus on the Australian context. The Bettering the Evaluation and Care of Health programme included 489900 crosssectional GP encounters where OA was managed from 2005 to $2010 .{ }^{13}$ Results showed that rates of using core non-pharmacological treatments as first-line management were low, and surgical referral rates were high. Medication management was mostly concordant with recommended practice apart from the overuse of opioids. Our earlier surveys of people with hip or knee OA found that use of core treatments was generally low, ${ }^{67}$ and that only $10 \%$ were prescribed exercise during GP consultations. ${ }^{60}$ In addition, rates of referral for arthroscopic surgery for the management of knee $\mathrm{OA}$ pain were high $^{68}{ }^{69}$ despite evidence showing it is ineffective ${ }^{8}$ and guidelines advising against its use. ${ }^{9}$ Finally, there was a tendency for patients to have arthroplasty surgery without severe disease or without an adequate trial of conservative interventions. ${ }^{1870-72}$

\section{BCW Step 2: select and specify the target behaviours}

A convenience sample of nine GPs (GP advisory group) were surveyed about which of the 36 clinical practice guideline recommendations/quality indicators (see online supplemental additional file 1) they believed need to be targeted. The GPs were asked to rate each behaviour on four criteria: Impact of changing the behaviour on the desired outcome (patient pain, function, quality of life and/or healthcare costs); likelihood of changing the behaviour; potential for spill-over, that is, the positive or negative impact of that behaviour on other desired behaviours; and ease of measurement. ${ }^{35}$ Survey respondents were asked to choose their top five recommendations based on their ratings. The top 20 ranked items are shown in table 1.

The PARTNER model development group including researchers and stakeholders discussed these as possible behaviours to target. The list was refined to nine target behaviours (table 1). Behaviours to not do something were excluded because they are much harder to change than behaviours to do something. ${ }^{73}$ Behaviours were also excluded if they were considered too ambiguous to target, such as if it was unclear when the behaviour should and/or should not be performed or if the recommendation was controversial or likely to be revised in the future. Finally, behaviours were excluded if evidence for a gap between the recommendation and current clinical practice was lacking. With the goal of having fewer than five behaviours to target, ${ }^{35}$ our expert group rated the nine remaining behaviours using the same four criteria to arrive at a short list of three target behaviours. An additional behaviour was added which was essential to the operation of the PARTNER model-referral to the CST.

Table 2 details the four 'target' behaviours. These target behaviours were thought to address, either directly or indirectly, the most important evidence-practice gaps in relation to the GPs role in the PARTNER model. We speculated that spending more time conversing about exercise/physical activity and weight loss, and discussing 
Table 1 The 20 highest ranked behaviours from the partner GP advisory group survey to identify the GP behaviours to target

\section{Ranking Behaviour}

\begin{tabular}{|c|c|}
\hline 1 & $\begin{array}{l}\text { GP determines patient's health education needs, health beliefs, goals, expectations of treatment, treatment preferences and } \\
\text { readiness to self-manage. }\end{array}$ \\
\hline 2 & GP does not refer patients for arthroscopy of the joint to manage OA pain. \\
\hline 3 & $\begin{array}{l}\text { GP provides education/advice to patients about the importance of general physical activity in the consultation and reinforced as } \\
\text { appropriate. }\end{array}$ \\
\hline 4 & $\begin{array}{l}\text { GP provides advice/education to patients about the use of self-management strategies such as appropriate footwear, gait } \\
\text { aids, thermal treatments as appropriate. }\end{array}$ \\
\hline 5 & GP does not refer the patient for an X-ray or MRI unless this is necessary to exclude other differential diagnoses. \\
\hline 6 & GP manages mood disorders (depression/anxiety) according to guidelines and provides referral as appropriate. \\
\hline 7 & $\begin{array}{l}\text { GP only offers intra-articular corticosteroid injections as an adjunct to non-drug conservative management if the patient has } \\
\text { moderate-severe pain that does not respond to, or cannot tolerate, other analgesic medications or NSAIDs. }\end{array}$ \\
\hline 8 & $\begin{array}{l}\text { GP makes and gives a diagnosis of OA clinically without imaging or other investigations if a person is } 45 \text { or over and has } \\
\text { activity related joint pain and has no morning stiffness lasting no longer than } 30 \mathrm{~min} \text {. }\end{array}$ \\
\hline 9 & $\begin{array}{l}\text { GP refers to an orthopaedic surgeon for consideration of joint replacement surgery: (1) if the patient has severe pain } \\
\text { or substantially impaired function and quality of life despite course of non-surgical treatment and ( } 2 \text { ) it is the patient } \\
\text { preference after they have been provided with detailed information about benefits and risks of surgery and the potential } \\
\text { consequences of not having or having surgery and recovery and rehabilitation after surgery. }\end{array}$ \\
\hline 10 & GP provides a referral to a formal weight loss programme or dietician when patient has a BMl $\geq 25 \mathrm{~kg} / \mathrm{m}^{2}$. \\
\hline 11 & GP assesses patient's pain. \\
\hline 12 & $\begin{array}{l}\text { GP provides education/advice to patients about the importance of regular strengthening and/or aerobic exercise in the } \\
\text { consultation and reinforced as appropriate. }\end{array}$ \\
\hline 13 & $\begin{array}{l}\text { GP provides education/advice to patients about the importance of maintaining a healthy weight or weight loss in the } \\
\text { consultation and reinforces as appropriate. }\end{array}$ \\
\hline 14 & GP assesses the patient's BMI. \\
\hline 15 & GP provides information and education about the nature of $\mathrm{OA}$, its causes and consequences including pain and prognosis. \\
\hline 16 & $\begin{array}{l}\text { GP offers a short course opioid prescription only if the patient has moderate-severe pain that does not respond to, or cannot } \\
\text { tolerate, other analgesic medications or NSAIDs and joint replacement surgery is contraindicated or delayed. Note: This } \\
\text { recommendation is likely to be revised in future due to increased concerns related to opioid toxicity and abuse. }\end{array}$ \\
\hline 17 & $\begin{array}{l}\text { GP does not recommend glucosamine or chondroitin. Note: Since this recommendation remains controversial, it was suggested } \\
\text { that the behaviour be worded: GP provides evidence-based advice regarding use of complementary/ complementary medicine. }\end{array}$ \\
\hline 18 & GP offers paracetamol as the first option for pain relief medication. \\
\hline 19 & GP can offer topical NSAIDs when patients have joint symptoms (pain/swelling). \\
\hline 20 & $\begin{array}{l}\text { In patients with pain despite more conservative interventions GP offers oral NSAIDs and in patients with gastrointestinal risk factors } \\
\text { these are coprescribed with a PPI or a COX-2 specific inhibitor. }\end{array}$ \\
\hline
\end{tabular}

The GPs were asked 'of all the behaviours presented which would you consider the top five to target?' the BOLD items are the nine remaining after stakeholder group discussion.

BMI, body mass index; GP, general practitioner; NSAIDs, non-steroidal anti-inflammatory drugs; OA, osteoarthritis; PPI, patient and public involvement.

referral to the CST, might have a spill-over effect of reducing undesirable practices including inappropriate imaging, prescribing stronger pain medications, and referring for arthroscopy and arthroplasty. We determined it was unrealistic to expect all GPs to develop skills to competently and confidently devise and deliver individualised exercise and/or weight loss programmes in the available consultation time, thus their role for target behaviours \#2 and \#3 was to give generic information that exercise and weight loss are important for the long-term management knee OA symptoms and disease progression, and refer on to the CST (behaviour \#4).

BCW Step 3: identify what needs to change (behavioural analysis) A core component of the BCW is the theoretical model used to describe behaviour and guide intervention planning. The model, Capability/Opportunity/ Motivation-Behaviour (COM-B), hypothesises that behaviour occurs as a result of the interaction between one's capability (both psychological and physical), opportunity (social and physical) and motivation (reflective and automatic) and that changing behaviour involves changing one or more of these. The BCW identifies different intervention options that can be applied to shift the COM-B components and provides a systematic way of determining which intervention options are most likely to achieve the behavioural change(s) sought.

We conducted a systematic review and qualitative evidence synthesis of barriers and enablers to recommended management of $\mathrm{OA}^{37} 38$ and our own qualitative study to identify GPs' perspectives on providing exercise 
Table 2 Final list of four target behaviours with a summary of the majority of ratings and comments

\begin{tabular}{|c|c|c|c|c|}
\hline $\begin{array}{l}\text { Evidence of gap in current } \\
\text { practice }\end{array}$ & Impact on outcomes & Likelihood of change & Potential for positive spill-over & $\begin{array}{l}\text { Ease of } \\
\text { measurement }\end{array}$ \\
\hline \multirow[b]{2}{*}{$\begin{array}{l}\text { 1. GP makes and gives a } \\
\text { diagnosis of osteoarthritis } \\
\text { clinically without imaging or } \\
\text { other investigations if a person } \\
\text { is } 45 \text { years or over and has } \\
\text { activity related joint pain and } \\
\text { has morning stiffness lasting no } \\
\text { longer than } 30 \text { min. }\end{array}$} & Very promising. & Promising. & Very promising. & Very promising. \\
\hline & $\begin{array}{l}\text { Making and giving } \\
\text { diagnosis may lead to better } \\
\text { management overall and } \\
\text { consequently improved pain } \\
\text { and function, as well as } \\
\text { cost and time savings and } \\
\text { reduction in harms from using } \\
\text { X-rays to explain OA. }\end{array}$ & $\begin{array}{l}\text { Likely to be some barriers } \\
\text { to this behavioural change, } \\
\text { including habit, GP confidence, } \\
\text { patient acceptance of a clinical } \\
\text { diagnosis, GP attending } \\
\text { education and accepting the } \\
\text { clinical practice guideline } \\
\text { recommendation. }\end{array}$ & $\begin{array}{l}\text { Positive spill-over to less } \\
\text { inappropriate use of imaging, patient } \\
\text { being given specific diagnosis } \\
\text { leading to better understanding of } \\
\text { prognosis and more likely to engage } \\
\text { with interventions. }\end{array}$ & $\begin{array}{l}\text { Imaging } \\
\text { referrals or } \\
\text { chart audit. }\end{array}$ \\
\hline \multirow[b]{2}{*}{$\begin{array}{l}\text { 2. GP provides education/ } \\
\text { advice to patients about } \\
\text { the importance of general } \\
\text { physical activity and regular } \\
\text { strengthening and/or aerobic } \\
\text { exercise during the consultation } \\
\text { which is reinforced at later } \\
\text { opportunities. }\end{array}$} & \multirow[b]{2}{*}{ Very promising. } & Promising. & Very promising. & Promising. \\
\hline & & $\begin{array}{l}\text { Able to be incorporated into } \\
\text { short appointment time. GPs } \\
\text { can be supplied with written } \\
\text { material to provide to patients } \\
\text { during consultation. Able to } \\
\text { use prompts. Requires change } \\
\text { of GP habit. Potential barrier } \\
\text { is GP confidence in giving } \\
\text { individualised advice. }\end{array}$ & $\begin{array}{l}\text { Positive spill-over to less time spent } \\
\text { prescribing or discussing surgical } \\
\text { interventions. }\end{array}$ & $\begin{array}{l}\text { Self-audit } \\
\text { or patient- } \\
\text { reported } \\
\text { questionnaire. }\end{array}$ \\
\hline \multirow{2}{*}{$\begin{array}{l}\text { 3. GP provides education/ } \\
\text { advice to patients either about } \\
\text { the importance of maintaining a } \\
\text { healthy weight or weight loss in } \\
\text { the initial consultation which is } \\
\text { reinforced at later opportunities. }\end{array}$} & \multirow{2}{*}{ Very promising. } & Promising. & Very promising. & Promising. \\
\hline & & $\begin{array}{l}\text { Requires significant education } \\
\text { and training. GPs can be } \\
\text { supplied with written material } \\
\text { to provide to patients during } \\
\text { consultation. Able to use } \\
\text { prompts. }\end{array}$ & $\begin{array}{l}\text { Positive spill-over to less time spent } \\
\text { prescribing or discussing surgical } \\
\text { interventions. }\end{array}$ & $\begin{array}{l}\text { Self-audit } \\
\text { or patient- } \\
\text { reported } \\
\text { questionnaire. }\end{array}$ \\
\hline \multirow[b]{2}{*}{$\begin{array}{l}\text { 4. GP refers patients with a } \\
\text { diagnosis of knee osteoarthritis } \\
\text { to the Care Support Team } \\
\text { which will provide further } \\
\text { assessment, advice, and } \\
\text { behavioural change and self- } \\
\text { management support. }\end{array}$} & \multirow[t]{2}{*}{ Promising. } & Promising. & Very promising. & Very promising. \\
\hline & & $\begin{array}{l}\text { Requires education. Able to } \\
\text { easily be incorporated into } \\
\text { a short appointment time. } \\
\text { Potential to use prompts and } \\
\text { desktop software. }\end{array}$ & $\begin{array}{l}\text { Spill-over to other behaviour such } \\
\text { as reduced referral for invasive } \\
\text { procedures, more support for } \\
\text { patients to engage in exercise } \\
\text { and weight loss. Reduced passive } \\
\text { mindset that occurs with referral for } \\
\text { surgery consult to 'fix' the knee. }\end{array}$ & $\begin{array}{l}\text { Chart audit } \\
\text { or referrals } \\
\text { received. }\end{array}$ \\
\hline
\end{tabular}

GPs were asked to rate each behaviour as 'very promising', 'promising', 'unpromising but worth considering' or 'not worth considering' for each of the four criteria. GP, general practitioner; OA, osteoarthritis.

and weight loss advice to patients with knee OA. ${ }^{39}$ In addition, we resurveyed our GP advisory group for their perspectives on the feasibility of the target behaviours (see online supplemental additional file 2). We amalgamated and organised the findings using the COM-B model as a framework for the behavioural analysis. Key findings were GPs' tendency to see the knee OA problem as relatively low importance and/or easy to manage, using a biomedical approach to explain and manage the condition, and a lack of knowledge and communication skills for effective discussions about the diagnosis, prognosis and non-drug, non-surgical treatment options. A belief that patients would or could not adopt the advice to exercise and lose weight, plus a lack of belief in the effectiveness of these interventions were also drivers of sub-optimal practice. Further, the constraints on changing practice afforded by the system (time and resources) and practice habits were identified as major barriers. Potential enablers included the professional requirement for continuing education, availability of desktop software and the normal practice routine of referring on to other health professionals and services.

\section{BCW step 4: identify appropriate intervention options}

The next step in the BCW was to identify the intervention options that would be most likely to effect behavioural change in GPs given the identified barriers. This process involved iterative discussion within the development team according to the APEASE criteria (Affordability, Practicability, Effectiveness and cost-effectiveness, Acceptability, Side effects/safety and Equity). ${ }^{35}$ Since all COM-B components, except physical capability, were relevant to our target behaviours, all nine intervention options were considered for the PARTNER GP behavioural change intervention, however, the three intervention options most applicable were: education, training and environmental restructuring.

BCW step 5: identify the behavioural change techniques to achieve the desired intervention options

Informed by the development group and by literature for effective techniques to achieve behavioural change in GPs, specific behavioural change techniques that could be used to achieve the desired intervention options were selected. There are numerous behavioural change 
techniques that can be used to deliver the intervention options we prioritised; however, many were unsuitable or impractical for our context and purpose. Behavioural change techniques included in the PARTNER GP behavioural change intervention were self-monitoring of behaviours, feedback on behaviour, provide information on where and when to perform behaviours, instruction on how to perform the behaviours, model/demonstrate the behaviours, credible source, prompts/cues, restructuring the physical environment, habit formation and adding objects to the environment.

\section{BCW step 6: determine the mode of delivery of the behavioural change techniques/intervention options}

The final step was to develop each intervention option and associated behavioural change techniques into the behavioural change interventions. For this we considered the current systems for continuing professional education for GPs and the GP practice software. The PARTNER GP behavioural change intervention includes an online professional development training package, a self-audit/ feedback tool and a desktop support platform for decision and referral support. For the online training package, we enlisted the help of educational experts and used feedback from our GP advisory group. Behavioural change theory and contemporary pedagogy for online education and adult learning were incorporated into the design and delivery of the content. The package consists of an online professional development module about management of knee OA created and delivered in collaboration with the Royal Australian College of General Practitioners (RACGP). Completers attain RACGP Continuing Medical Education points. An additional PARTNER model-specific education and training module was created and managed by the PARTNER team incorporating brief training on communication techniques and how to deliver advice to patients about exercise/physical activity and weight loss. The self-audit/feedback tool involved the summarising of clinical performance (audit) over time, provision of that summary (feedback) to individual GPs with the aim of motivating behavioural change, and links to resources to facilitate change. Audit/feedback is one of the most widely used and effective interventions in implementation research. ${ }^{74}$ The self-audit/feedback component of the PARTNER GP behavioural change intervention incorporated recommended features ${ }^{75}$ and was developed according to RACGP guidance to accrue continuing medical education points for incentivisation. All professional development and audit/feedback activities were available wholly online to enable cost-effective large-scale roll-out.

For the decision and referral support, we identified an existing electronic care planning and medical record software platform already operating in many GP practices with the capability to adapt a care plan for decision support for knee OA management consistent with the PARTNER model, enable referral to the CST and facilitate communication with the CST staff. A one-sheet printable patient education resource was also embedded in the care planning tool. The content of the information sheet was developed with wide stakeholder input including patients and a lay language expert. A summary of the content of each of the components is provided in online supplemental additional file 3 .

\section{Stage 3: operationalising the new service (CST)}

For people with knee OA, failure to achieve optimal outcomes is primarily due to: (1) limited uptake and adherence to lifestyle behaviours such as exercise and weight $\operatorname{loss}^{76-78}$ and (2) overuse of non-evidence-based, low-value or high-risk treatments such as complementary and alternative medicines, opioid medications and arthroscopy surgery. ${ }^{79-81}$ The CST role was to address these behaviours with a biopsychosocial, patient-centred approach to care planning and behavioural change support. Table 3 shows the features of the CST mapped to our list of the 36 clinical practice guideline recommendations/quality indicators that constitute optimal care (from stage 1).

The main tasks in the operationalisation of the CST service were: (1) identifying and training clinicians in OA management, communication and health behavioural change skills, (2) developing the service delivery procedures and setting up the remote-delivery hardware and software, (3) developing patient resources to promote health literacy and effective self-management, (4) sourcing adjunct services and (5) designing patient and GP engagement strategies.

\section{Staff recruitment and training}

Staff with allied health backgrounds recruited for the CST were trained in evidence-based knee OA management via bespoke online modules and face-to-face sessions, and in communication and behavioural change with HealthChange Australia methodology via 2.5 days of face-to-face workshops and supported practice. ${ }^{82}$

\section{CST service procedures and delivery systems}

Patients referred to the CST by their GP receive 2-12 contacts in a 12-month period, with most of the contact expected to occur in the first 6 months. The number and timing are flexible and depend on patient needs and preferences. The population targeted by the intervention is heterogeneous with respect to factors such as age, disease severity, socioeconomic level, geography, employment status, health literacy and culture. The PARTNER model allows the CST service to be responsive to new evidence and facilitates quality control through ongoing training and peer support. Consultations are delivered by telephone, supported by email communication and websites, and with consultation data recorded digitally using Research Electronic Data Capture. ${ }^{83}$

\section{Patient resources}

We conducted a comprehensive audit of available resources (websites and printed material) with help from Arthritis Australia. Most resources did not provide information consistent with the PARTNER model. The 
Table 3 The CST service features to provide best-practice primary care for people with knee OA mapped to the 36 key recommendations formulated in stage 1

Components of optimal care (key recommendations)

\section{CST service features}

Diagnosis, assessment and general management

1. Diagnosis is reached clinically without use of imaging or other investigations unless history or physical examination suggest alternative diagnosis

Focus on improving health literacy in relation to knee OA with verbal and written education material. Patients understand how the disease can be diagnosed based on clinical findings. Education resources included a modified version of the Guidebook for Managing Knee OA developed by Arthritis UK, the Arthritis Australia My Joint Pain website (www.MyJointPain.com.au), and the painHEALTH website (www.painHEALTH.csse.uwa.edu.au)

2. Patient receives information and education about the nature of Focus on improving health literacy in relation to knee OA with verbal and written $\mathrm{OA}$, its causes and consequences including pain and prognosis education material.

3-5. Pain, function, and BMI are assessed

Patient given survey to complete before first consultation including assessment of pain, function and BMI.

6. Fatigue levels, sleep and mood are assessed using reliable self- Patient given survey to complete before first consultation including validated reported instruments

fatigue, sleep and mood scales.

7. A comprehensive initial biopsychosocial assessment including CST trained in delivering biopsychosocial assessment and management guided participation (work/education, leisure, social roles), health education by patient's needs and preferences, and to explore health beliefs and education needs, health beliefs and motivation and self-efficacy to selfmanage

8. Physical status (eg, joint status, mobility, strength, joint alignment, proprioception, posture) is assessed

9. Patient's health education needs, health beliefs, goals, expectations of treatment, treatment preferences and readiness to self-manage are assessed

10. A written personalised management plan including SMART goals and treatment options is formulated with the patient and a copy is provided to the patient

11. The patient has regular review appointments with a health professional scheduled

Non-drug, conservative management

12. Information/advice is provided to the patient about the importance of muscle strengthening exercise and general physical activity

\section{A referral to a physiotherapist is provided when physiotherapy} is indicated

14. Strategies to assist the patient to adhere to exercise/physical activity behaviours (eg, health coaching) are employed

15. Information/advice is provided to patients about the importance of maintaining a healthy weight or weight loss if overweight or obese

16. A formal weight loss programme or referral to dietician is provided when patient has a $\mathrm{BMI} \geq 25 \mathrm{~kg} / \mathrm{m}^{2}$

17. Strategies to assist the patient to adhere to dietary modifications or weight loss programme are employed

18. Advice about activity pacing is provided

19. A patient-centred approach should be adopted and secondary problems including co-morbidities, mood disorders, sleep disturbance, and fatigue, should be managed, consistent with a biopsychosocial approach to managing chronic pain conditions.

20. Mood disorders (depression/anxiety) are assessed using a valid screening tool and, when indicated, management is provided according to recommended practice.

\section{Support and advice is provided to patients to facilitate self-} management and on the use of self-treatment strategies such as appropriate footwear, TENS, and thermal agents as appropriate needs before delivering education.

CST trained in delivering biopsychosocial assessment and management guided by patient's needs and preferences.

CST trained in delivering biopsychosocial assessment and management guided by patient's needs and preferences.

A 'Patient Self-Management Plan' is completed in collaboration with the patient and a copy emailed to the patient.

Patient has access to the CST for up to 12 consultations in 1 year.

Focus on improving health literacy in relation to knee OA with verbal and written education material.

CST can suggest seeing a local physiotherapist if patient has difficulty with adherence or has special exercise needs.

CST trained in supporting health behavioural change by HealthChange Australia.

Focus on improving health literacy in relation to knee OA with verbal and written education material.

Access to a commercial remotely-delivered weight loss or healthy eating programme-the CSIRO Total Well-being Diet (https://www.totalwellbeingdiet.com/ au/).

CST trained in supporting health behavioural change in accordance with care plan.

Focus on improving health literacy in relation to knee OA with verbal and written education material.

Patient encouraged to explore other areas for change in addition to core options of exercise and weight loss, including managing other healthy lifestyle factors, monitoring and managing symptoms and triggers, accessing relevant services and information, and managing OA medications effectively. If PROMISE Sleep Score $\geq 20$ patients suggested the cognitive behavioural therapy (CBT)-based insomnia course from 'This Way Up' (https://thiswayup.org.au/).

Mood is assessed using the PHQ Depression subscale. A score of $\geq 20$ will trigger an urgent referral to GP. Patients who identify low mood or anxiety as a priority problem will have access to the CBT-based online depression and anxiety course from 'This Way Up' (https://thiswayup.org.au/).

Focus on improving health literacy in relation to knee OA with verbal and written education material. 
Table 3 Continued

\begin{tabular}{ll}
\hline Components of optimal care (key recommendations) & CST service features \\
$\begin{array}{l}\text { 22. Walking aids and assistive devices to improve activities of daily } \\
\text { living are recommended as indicated }\end{array}$ & $\begin{array}{l}\text { Focus on improving health literacy in relation to knee OA with verbal and written } \\
\text { education material. Appropriate patients directed to a leaflet on the correct use of } \\
\text { a cane for people with knee OA. }\end{array}$ \\
$\begin{array}{l}\text { 23. For those at risk of work disability or who want to start/return to } \\
\text { work, vocational rehabilitation is provided }\end{array}$ & $\begin{array}{l}\text { Patients who identify work productivity as a significant issue on the Work } \\
\text { Productivity and Activity Impairment Questionnaire will be given information and } \\
\text { support for contacting their local vocational rehabilitation counsellor. }\end{array}$ \\
$\begin{array}{l}\text { 24. Patient is recommended psychological treatments to aid pain } \\
\text { management when indicated }\end{array}$ & $\begin{array}{l}\text { Patient with pain score } \geq 4 \text { on the NRS or severe pain reported as a priority problem } \\
\text { will be offered access to the CBT-based online pain coping skills training course: } \\
\text { 'PainTrainer' (www.paintrainer.org). }\end{array}$ \\
$\begin{array}{l}\text { Drug recommendations } \\
\text { 25-31. Appropriate and evidence-based medication } \\
\text { recommendations }\end{array}$ & $\begin{array}{l}\text { Patients who identify suboptimal effectiveness of pain medications or } \\
\text { unacceptable side effects will be referred to GP for medication review. }\end{array}$ \\
$\begin{array}{l}\text { Surgical management } \\
\text { 32-36. Appropriate and evidence-based surgical interventions }\end{array}$ & $\begin{array}{l}\text { Patients considering arthroplasty will be offered decision support based on the } \\
\text { Arthritis Australia's My Joint Pain website information (www.myjointpain.com). }\end{array}$
\end{tabular}

BMI, body mass index; CST, Care Support Team; OA, osteoarthritis.

resulting patient education resources for the PARTNER model consisted of the guidebook for managing knee OA developed by Arthritis $\mathrm{UK}^{84}$ and modified to suit the Australian context and two websites (table 3). The home-based PARTNER muscle strengthening exercise programme was developed by physiotherapists with expertise in developing and evaluating exercise interventions for knee $\mathrm{OA}^{85}$ and is available in both web-based and print formats.

\section{Adjunct services}

Evidence-based adjunct services were identified and embedded in the management options as part of the CST service. Adjunct services included online cognitive behavioural therapy-based programmes for pain coping skills training, and managing depression, anxiety or sleep problems; and a weight loss/healthy eating programme. ${ }^{86}$

\section{Engagement strategies}

We conducted empirical qualitative research to ascertain factors that would enhance or inhibit GP engagement with the CST. ${ }^{43}$ Our findings highlighted that GPs had concerns about confusion caused by incongruence of information and advice, the possibility of the service conflicting with other schemes/initiatives, and perceived loss of control of patient care. Many did not believe there was a need for the proposed service or that there would be benefits, disclosed resistance to change, and expressed reluctance to trust in the skills and abilities of the health professionals providing the care support. In contrast, some GPs recognised the potential benefits of the model. Responding to these findings, we embedded regular reporting to the patient's GP into the service protocols and created an information brochure for GPs that addressed many of their concerns. Patient engagement was facilitated by a bespoke brochure about the CST that could be printed from the GP's desktop electronic medical record software.

\section{DISCUSSION}

This project aimed to address the current shortfalls in primary care management of people with knee OA, first by developing a new model of service delivery (the PARTNER model) to deliver recommended care, then planning a behavioural change intervention targeting GPs, and finally operationalising the new CST service. This paper describes the systematic and comprehensive approach to developing this complex implementation strategy including both a novel service delivery model and a clinician behavioural change intervention. ${ }^{19} 3587$ Embedded in the process was consideration of stakeholder views and the contextual constraints of our setting, and empirical investigation of GP behaviour and barriers to engagement with the new model. We harnessed technologies to provide efficiency and overcome access issues. The project was undertaken by a multisite, multidisciplinary group with broad stakeholder input at several stages. The PARTNER model addresses many of the identified barriers to recommended practice and incorporates evidence-based components of chronic disease models of care $^{134648}$ and knowledge translation interventions. ${ }^{3688}$

\section{Behavioural change wheel}

The BCW was developed to integrate a number of behavioural change theories and frameworks with the purpose of simplifying the process and addressing the challenges experienced by intervention developers facing a confusing array of theory options. ${ }^{36} 89$ The sequential steps in the BCW provided a systematic and transparent approach to developing an intervention which facilitated subsequent implementation and evaluation. It was hypothesised to improve the chance of successfully achieving the desired change. ${ }^{36}$ Since the BCW approach is relatively novel, this report also provides an example of the application of the approach as an opportunity for further evaluation and refinement. 


\section{Challenges and strengths of the partner model}

The project targets a heterogeneous patient population with a wide range of needs. The PARTNER model allows for a high degree of flexibility and individual tailoring of management, necessary for both engagement and efficacy. However, the model involves GPs, CST staff and patients all interacting with each other, which leads to potential for conflict of agendas and expectations. The inherent complexity also comes from the difficulty in achieving many of the behaviours required by both those delivering and receiving the care. The GPs are required to make a small number of changes but these are a significant shift from typical current practice. ${ }^{12} 90$ The CST are also required to perform behaviours outside their traditional practice. They are required to incorporate health behavioural change skills, tailor broad management options to the heterogeneous needs of patients and deliver the care remotely. Patients are required to undertake new behaviours around exercise, physical activity, weight loss and self-management, and these lifestyle changes are notoriously difficult for most people to achieve. Making explicit use of theory and following an established behavioural change intervention development framework is hoped to result in an effective implementation strategy design. ${ }^{19}$

One of the strengths of the PARTNER model is that it requires only relatively small changes by GPs with most of the change to patient care occurring because of the addition of the CST. Apart from the one-off training, there are no alterations to the amount of GP time or resources used in the PARTNER model from current clinical practice.

\section{Limitations and strengths of the development process}

An important limitation of the development process we undertook was that it was lengthy and resource intensive. However, the end result should have a greater chance of success than if a less systematic and comprehensive approach had been used. Second, there was still a degree of subjectivity in the development process as the members of the development group made decisions at various stages that were based on their own research and clinical practice experiences, beliefs and preconceptions. Similarly, gaining the opinions through focus groups and surveys of a wide range of stakeholders sourced from the community had some disadvantages. This was mainly due to some stakeholders holding beliefs inconsistent with research evidence and current recommended practice.

Limitations related to the behavioural change intervention targeting GPs include the possibility of barriers that we have not identified or addressed. Participating in the education and training component is a behaviour in itself and we did not undertake a process to ensure this behaviour occurs. Programmes requiring GP behavioural change are often unsuccessful ${ }^{73} 91$ especially if autonomy is threatened ${ }^{43}$ and we do not yet know whether the GPs will accept and engage with the CST as intended. Further, many GPs did not perceive there was an evidence-practice gap that needed addressing. ${ }^{39}$ Even some members of our
GP advisory group believed that advice about exercise, self-management, and weight loss, and referral to physiotherapy, are currently occurring routinely and effectively in general practice. These issues may lead to a failure to achieve GP behavioural change.

Limitations related to the CST component of the PARTNER model include the possible technology divide and other issues impeding engagement with the remotelydelivered service by patients. In addition, new nontraditional services and practitioner roles can be politically charged if major resource reallocation or threats to work patterns are the result. ${ }^{92}$ However, both these limitations can become strengths of the model in time.

In terms of strengths, the systematic, comprehensive and theory-driven process, we believe, will increase our chances of the model being implemented as planned and being effective in improving patient outcomes. Stakeholder involvement at several stages of the process kept the development team grounded in reality and cognisant of context. A further strength is the focussing on a few target behaviours and properly addressing them, rather than trying to change too much ${ }^{93}$ We believe the behaviours we have targeted will achieve important spillover to some of the other practice behaviours that are currently frequently suboptimally performed.

The UK Medical Research Council guidance for developing complex interventions asserts the importance of creating new evidence where gaps exist. As part of the PARTNER development process, we recognised there were gaps in our understanding of the target GP behaviours. New knowledge of the problems faced by GPs was generated and resulting in a better understanding of the reasons for their management behaviours. In undertaking our qualitative evidence synthesis, ${ }^{3738}$ our own qualitative interview studies, ${ }^{39} 43$ and consulting with our GP advisory group through surveys and focus groups, we have generated much needed knowledge to inform the specific content of our education and training interventions and the desktop software support for care planning.

\section{CONCLUSION}

This implementation project developed a new strategy to address known evidence practice gaps in managing people with knee OA. The resulting PARTNER model included the development of two interventions: (1) a GP behavioural change intervention (professional development including online education and audit/ feedback activities, and desktop software to support decision-making, referral and provision of related educational resources) and (2) the new CST service (remotely-delivered biopsychosocial assessment, education, treatment planning and care coordination by skilled multidisciplinary healthcare professionals). The interventions are based on existing and purposively generated new evidence, were developed following a systematic approach to intervention design and underpinned by theory. The resulting implementation strategy has been 
tested in a pilot study. Effectiveness of the PARTNER model will be fully evaluated in a cluster randomised trial currently underway, ${ }^{86}$ and a process evaluation that will investigate the effect of the GP behavioural change intervention on GP practice behaviour and the fidelity of the CST in delivering the PARTNER model service. ${ }^{94}$ This article has served to demonstrate the application of current best practice methods for developing and operationalising a complex implementation strategy.

\section{Author affiliations}

${ }^{1}$ Centre for Health Exercise \& Sports Medicine, University of Melbourne, Melbourne, Victoria, Australia

${ }^{2}$ Institute of Bone and Joint Research, Kolling Institute, The University of Sydney, Sydney, New South Wales, Australia

${ }^{3}$ Department of Rheumatology, Royal North Shore Hospital, Sydney, New South Wales, Australia

${ }^{4}$ Nuffield Department of Orthopaedics, Rheumatology and Musculoskeletal

Sciences, University of Oxford, Oxford, UK

${ }^{5}$ Centre for Behaviour Change, UCL, London, UK

${ }^{6}$ Department of General Practice, University of Melbourne, Melbourne, Victoria, Australia

\section{Twitter David J Hunter @ProfDavidHunter}

Acknowledgements We wish to acknowledge the voluntary contributions of the many stakeholders (including patients/consumers), working group participants, partner organisations and their representatives in the design of the PARTNER model and the ensuing study, in particular Ms Franca Marine and Ms Ainslie Cahill from Arthritis Australia for educational materials and advice, and Ms Jeanette Gale and Ms Caroline Bills from HealthChange Australia for behaviour change advice. The PARTNER Care Support Team collect and manage patient data using REDCap electronic data capture tools hosted at The University of Sydney.

Contributors KLB, RSH and DJH conceived the study. All authors (TE, RSH, DJH, JLB, PJAN, LA, MP and KLB) were involved in the planning and conduct of the work described in the paper and in revising the manuscript. TE wrote the initial manuscript draft and revisions. All authors have given final approval of the version to be published and agree to be accountable for all aspects of the work.

Funding The PARTNER model of service delivery and implementation strategy was supported with funding from the National Health and Medical Research Council (NHMRC) Centre of Research Excellence for Translational Research in Musculoskeletal Pain (APP1079078). In addition individual author funding includes: DJH is supported by a NHMRC Practitioner Fellowship (APP1079777). RSH is supported by an NHMRC Senior Research Fellowship (\#1154217). MP has been supported by an NHMRC Career Development Fellowship. KLB is supported by an NHMRC Principal Research Fellowship.

Competing interests DJH provides consulting advice to Pfizer, Lilly, Merck Serono and TLC bio. The remaining authors declare that they have no competing interests.

Patient and public involvement Patients and/or the public were involved in the design, or conduct, or reporting, or dissemination plans of this research. Refer to the Methods section for further details.

Patient consent for publication Not required.

Provenance and peer review Not commissioned; externally peer reviewed.

Data availability statement All data relevant to the study are included in the article, is uploaded as online supplementary additional files, is provided in companion articles or is publicly available (see References). Further information provided on reasonable request.

Open access This is an open access article distributed in accordance with the Creative Commons Attribution Non Commercial (CC BY-NC 4.0) license, which permits others to distribute, remix, adapt, build upon this work non-commercially, and license their derivative works on different terms, provided the original work is properly cited, appropriate credit is given, any changes made indicated, and the use is non-commercial. See: http://creativecommons.org/licenses/by-nc/4.0/.

\section{ORCID iDs}

Thorlene Egerton http://orcid.org/0000-0003-4751-7624
Rana S Hinman http://orcid.org/0000-0001-6368-9456

David J Hunter http://orcid.org/0000-0003-3197-752X

Jocelyn L Bowden http://orcid.org/0000-0002-0340-0232

Philippa J A Nicolson http://orcid.org/0000-0003-2394-4867

Lou Atkins http://orcid.org/0000-0001-9322-7869

Marie Pirotta http://orcid.org/0000-0003-4309-6885

Kim L Bennell http://orcid.org/0000-0003-4982-5639

\section{REFERENCES}

1 Bannuru RR, Osani MC, Vaysbrot EE, et al. OARSI guidelines for the non-surgical management of knee, hip, and polyarticular osteoarthritis. Osteoarthritis Cartilage 2019;27:1578-89.

2 Sakellariou G, Conaghan PG, Zhang W, et al. EULAR recommendations for the use of imaging in the clinical management of peripheral joint osteoarthritis. Ann Rheum Dis 2017;76:1484-94.

3 NICE. Osteoarthritis: care and management in adults. Clinical guideline CG177. London: National Institute for Health and Care Excellence, 2014.

4 Nelson AE, Allen KD, Golightly YM, et al. A systematic review of recommendations and guidelines for the management of osteoarthritis: the chronic osteoarthritis management initiative of the U.S. bone and joint initiative. Semin Arthritis Rheum 2014;43:701-12.

5 Fernandes L, Hagen KB, Bijlsma JWJ, et al. EULAR recommendations for the non-pharmacological core management of hip and knee osteoarthritis. Ann Rheum Dis 2013:72:1125-35.

6 Royal Australian College of General Practitioners. Guideline for the management of knee and hip osteoarthritis. 2nd edn. Royal Australian Collage of General Practitioners, 2018.

7 Kolasinski SL, Neogi T, Hochberg MC, et al. 2019 American college of rheumatology/arthritis foundation guideline for the management of osteoarthritis of the hand, hip, and knee. Arthritis Care Res 2020;72:149-62.

8 Thorlund JB, Juhl CB, Roos EM, et al. Arthroscopic surgery for degenerative knee: systematic review and meta-analysis of benefits and harms. Br J Sports Med 2015;49:1229-35.

9 American Academy of Orthopaedic Surgeons. Treatment of osteoarthritis of the knee: evidence-based guideline. 2nd edn. Rosemont, IL, 2013.

10 Buchbinder R, Richards B, Harris I. Knee osteoarthritis and role for surgical intervention: lessons learned from randomized clinical trials and population-based cohorts. Curr Opin Rheumatol 2014;26:138-44.

11 Basedow M, Esterman A. Assessing appropriateness of osteoarthritis care using quality indicators: a systematic review. J Eval Clin Pract 2015;21:782-9.

12 Runciman WB, Hunt TD, Hannaford NA, et al. CareTrack: assessing the appropriateness of health care delivery in Australia. Med J Aust 2012;197:100-5.

13 Brand CA, Harrison C, Tropea J, et al. Management of osteoarthritis in general practice in Australia. Arthritis Care Res 2014;66:551-8.

14 Australia A. The ignored majority. The voice of arthritis. A national survey to discover the impact of arthritis on Australians, 2011.

15 Australian Osteoarthritis Summit. White paper: developing strategic priorities in osteoarthritis research: proceedings and recommendations arising from the inaugural Australian osteoarthritis Summit, 2012: 1-36.

16 National Osteoarthritis Strategy Project Group. National osteoarthritis strategy. Sydney: University of Sydney, 2018

17 National Health Priority Action Council (NHPAC). National service improvement framework for osteoarthritis, rheumatoid arthritis and osteoporosis. Canberra: Australian Government Department of Health and Ageing, 2006.

18 Brand CA, Ackerman IN, Bohensky MA, et al. Chronic disease management: a review of current performance across quality of care domains and opportunities for improving osteoarthritis care. Rheum Dis Clin North Am 2013;39:123-43.

19 Craig P, Dieppe P, Macintyre S, et al. Developing and evaluating complex interventions: the new medical Research Council guidance. Int J Nurs Stud 2013;50:587-92.

20 Pinnock H, Barwick M, Carpenter CR, et al. Standards for reporting implementation studies (STARI): explanation and elaboration document. BMJ Open 2017;7:e013318.

21 Hoffmann TC, Glasziou PP, Boutron I, et al. Better reporting of interventions: template for intervention description and replication (TIDieR) checklist and guide. BMJ 2014;348:g1687.

22 Michie S, Atkins LS, West R. The behaviour change wheel: a guide to designing interventions. Silverback Publishing, 2014. 
23 Michie S, van Stralen MM, West R. The behaviour change wheel: a new method for characterising and designing behaviour change interventions. Implement Sci 2011;6:42.

24 Egerton T, Diamond L, Buchbinder R, et al. Barriers and enablers in primary care clinicians' management of osteoarthritis: protocol for a systematic review and qualitative evidence synthesis. BMJ Open 2016;6:e011618.

25 Egerton T, Diamond LE, Buchbinder R, et al. A systematic review and evidence synthesis of qualitative studies to identify primary care clinicians' barriers and enablers to the management of osteoarthritis. Osteoarthritis Cartilage 2017;25:625-38.

26 Egerton T, Nelligan RK, Setchell J, et al. General practitioners' views on managing knee osteoarthritis: a thematic analysis of factors influencing clinical practice guideline implementation in primary care. BMC Rheumatol 2018;2:30.

27 Hinman RS, Nelligan RK, Bennell KL, et al. "Sounds a bit crazy, but it was almost more personal:" a qualitative study of patient and clinician experiences of physical therapist-prescribed exercise fo knee osteoarthritis via skype. Arthritis Care Res 2017;69:1834-44.

28 Lawford BJ, Delany C, Bennell KL, et al. "I was really pleasantly surprised": firsthand experience and shifts in physical therapist perceptions of telephone-delivered exercise therapy for knee osteoarthritis-a qualitative study. Arthritis Care Res 2019;71:545-57.

29 Lawford BJ, Delany C, Bennell KL, et al. "I was really sceptical...But it worked really well": a qualitative study of patient perceptions of telephone-delivered exercise therapy by physiotherapists for people with knee osteoarthritis. Osteoarthritis Cartilage 2018;26:741-50.

30 Egerton T, Nelligan R, Setchell J, et al. General practitioners' perspectives on a proposed new model of service delivery for primary care management of knee osteoarthritis: a qualitative study. BMC Fam Pract 2017:18:85.

31 Brouwers MC, Kho ME, Browman GP, et al. Development of the agree II, part 1: performance, usefulness and areas for improvement. CMAJ 2010;182:1045-52.

32 Brouwers MC, Kho ME, Browman GP, et al. Development of the agree II, part 2: assessment of validity of items and tools to support application. CMAJ 2010;182:E472-8.

33 McAlindon TE, Bannuru RR, Sullivan MC, et al. OARSI guidelines for the non-surgical management of knee osteoarthritis. Osteoarthritis Cartilage 2014;22:363-88.

34 Hochberg MC, Altman RD, April KT, et al. American college of rheumatology 2012 recommendations for the use of nonpharmacologic and pharmacologic therapies in osteoarthritis of the hand, hip, and knee. Arthritis Care Res 2012;64:465-74.

35 Edwards JJ, Khanna M, Jordan KP, et al. Quality indicators for the primary care of osteoarthritis: a systematic review. Ann Rheum Dis 2015;74:490-8

36 Australian Commission on Safety and Quality in Health Care. Practice-level indicators of safety and quality for primary health care specification, version 1.0. Sydney: ACSQHC, 2012.

37 Schmittdiel J, Mosen DM, Glasgow RE, et al. Patient assessment of chronic illness care (PACIC) and improved patient-centered outcomes for chronic conditions. J Gen Intern Med 2008;23:77-80.

38 Agency for Clinical Innovation Musculoskeletal Network. Osteoarthritis chronic care program model of care. Chatswood, NSW, Australia: Agency for Clinical Innovation, 2012.

39 Arthritis Alliance of Canada. Tool for developing and evaluating models of care. Canada: Arthritis Alliance of Canada, 2012.

40 Dziedzic KS, Healey EL, Porcheret M, et al. Implementing core NICE guidelines for osteoarthritis in primary care with a model consultation (mosaics): a cluster randomised controlled trial. Osteoarthritis Cartilage 2018;26:43-53.

41 Jordan KP, Edwards JJ, Porcheret M, et al. Effect of a model consultation informed by guidelines on recorded quality of care of osteoarthritis (MOSAICS): a cluster randomised controlled trial in primary care. Osteoarthritis Cartilage 2017;25:1588-97.

42 Skou ST, Roos EM. Good Life with osteoArthritis in Denmark (GLA:DTM): evidence-based education and supervised neuromuscular exercise delivered by certified physiotherapists nationwide. BMC Musculoskelet Disord 2017;18:72.

43 Østerås N, van Bodegom-Vos L, Dziedzic K, et al. Implementing international osteoarthritis treatment guidelines in primary health care: study protocol for the SAMBA stepped wedge cluster randomized controlled trial. Implement Sci 2015;10:165.

44 Speerin R, Slater H, Li L, et al. Moving from evidence to practice: models of care for the prevention and management of musculoskeletal conditions. Best Pract Res Clin Rheumatol 2014:28:479-515.

45 Brand CA, Ackerman IN, Tropea J. Chronic disease management: improving care for people with osteoarthritis. Best Pract Res Clin Rheumatol 2014:28:119-42.
46 Zwar N, Harris M, Griffiths R, et al. A systematic review of chronic disease management. Sydney, Australia: Australian Primary Health Care Research Institute, The University of New South Wales School of Public Health and Community Medicine, 2006.

47 Briggs AM, Chan M, Slater $\mathrm{H}$. Models of care for musculoskeletal health: moving towards meaningful implementation and evaluation across conditions and care settings. Best Pract Res Clin Rheumatol 2016;30:359-74.

48 Wagner EH. Chronic disease management: what will it take to improve care for chronic illness? Eff Clin Pract 1998;1:2-4.

49 Hunt MA, Birmingham TB, Skarakis-Doyle E, et al. Towards a biopsychosocial framework of osteoarthritis of the knee. Disabil Rehabil 2008;30:54-61.

50 Ackerman IN, Buchbinder R, Osborne RH. Factors limiting participation in arthritis self-management programmes: an exploration of barriers and patient preferences within a randomized controlled trial. Rheumatology 2013;52:472-9.

51 Cuperus N, Hoogeboom TJ, Kersten CC, et al. Randomized trial of the effectiveness of a non-pharmacological multidisciplinary face-toface treatment program on daily function compared to a telephonebased treatment program in patients with generalized osteoarthritis. Osteoarthritis Cartilage 2015;23:1267-75.

52 Goode AD, Reeves MM, Eakin EG. Telephone-delivered interventions for physical activity and dietary behavior change: an updated systematic review. Am J Prev Med 2012;42:81-8.

53 Bennell KL, Nelligan R, Dobson F, et al. Effectiveness of an internetdelivered exercise and pain-coping skills training intervention for persons with chronic knee pain: a randomized trial. Ann Intern Med 2017;166:453-62.

54 Hinman RS, Campbell PK, Lawford BJ, et al. Does telephonedelivered exercise advice and support by physiotherapists improve pain and/or function in people with knee osteoarthritis? Telecare randomised controlled trial. Br J Sports Med 2020;54:790-7.

55 Russell TG, Buttrum P, Wootton R, et al. Internet-based outpatient telerehabilitation for patients following total knee arthroplasty: a randomized controlled trial. J Bone Joint Surg Am 2011;93:113-20.

56 Salisbury C, Montgomery AA, Hollinghurst S, et al. Effectiveness of PhysioDirect telephone assessment and advice services for patients with musculoskeletal problems. Br J Sports Med 2014;48:1391.

57 Hollinghurst S, Coast J, Busby J, et al. A pragmatic randomised controlled trial of 'PhysioDirect' telephone assessment and advice services for patients with musculoskeletal problems: economic evaluation. BMJ Open 2013;3:e003406.

58 Mason P, Barnes M. Constructing theories of change: methods and sources. Evaluation 2007;13:151-70.

59 Arthritis Australia. Time to move: ostearthritis: arthritis Australia, 2014.

60 Nicolson PJA, Hinman RS, French SD, et al. Improving adherence to exercise: do people with knee osteoarthritis and physical therapists agree on the behavioral approaches likely to succeed? Arthritis Care Res 2018;70:388-97.

61 Holden MA, Nicholls EE, Young J, et al. UK-based physical therapists' attitudes and beliefs regarding exercise and knee osteoarthritis: findings from a mixed-methods study. Arthritis Rheum 2009;61:1511-21.

62 Briggs AM, Houlding E, Hinman RS, et al. Health professionals and students encounter multi-level barriers to implementing high-value osteoarthritis care: a multi-national study. Osteoarthritis Cartilage 2019;27:788-804.

63 Briggs AM, Hinman RS, Darlow B, et al. Confidence and attitudes toward osteoarthritis care among the current and emerging health workforce: a multinational interprofessional study. ACR Open Rheumatol 2019;1:219-35.

64 Rosemann T, Wensing M, Joest K, et al. Problems and needs for improving primary care of osteoarthritis patients: the views of patients, general practitioners and practice nurses. BMC Musculoskelet Disord 2006; 7:48.

65 Arthritis Australia. Whose problem is it anyway? The voice of GP's on Arthritis. Arthritis Australia, 2012.

66 Briggs AM, Towler SCB, Speerin R, et al. Models of care for musculoskeletal health in Australia: now more than ever to drive evidence into health policy and practice. Aust Health Rev 2014;38:401-5

67 Hinman RS, Nicolson PJA, Dobson FL, et al. Use of nondrug, nonoperative interventions by community-dwelling people with hip and knee osteoarthritis. Arthritis Care Res 2015;67:305-9.

68 Buchbinder R, Harris IA. Arthroscopy to treat osteoarthritis of the knee? Med J Aust 2012:197:364-5.

69 Bohensky MA, Sundararajan V, Andrianopoulos N, et al. Trends in elective knee arthroscopies in a population-based cohort, 20002009. Med J Aust 2012;197:399-403. 
70 Porcheret M, Jordan K, Jinks C, et al. Primary care treatment of knee pain-a survey in older adults. Rheumatology 2007;46:1694-700.

71 Hunter DJ. Quality of osteoarthritis care for community-dwelling older adults. Clin Geriatr Med 2010;26:401-17.

72 Ackerman IN, Bohensky MA, de Steiger R, et al. Substantial rise in the lifetime risk of primary total knee replacement surgery for osteoarthritis from 2003 to 2013: an international, population-level analysis. Osteoarthritis Cartilage 2017;25:455-61.

73 Grol R. Successes and failures in the implementation of evidencebased guidelines for clinical practice. Med Care 2001;39:||46-II54.

74 Ivers N, Jamtvedt G, Flottorp S, et al. Audit and feedback: effects on professional practice and healthcare outcomes. Cochrane Database Syst Rev 2012;154:CD000259.

75 Ivers NM, Sales A, Colquhoun H, et al. No more 'business as usual' with audit and feedback interventions: towards an agenda for a reinvigorated intervention. Implement Sci 2014;9:14.

76 Conaghan PG, Porcheret M, Kingsbury SR, et al. Impact and therapy of osteoarthritis: the arthritis care oa nation 2012 survey. Clin Rheumatol 2015;34:1581-8.

77 Howarth D, Inman D, Lingard E, et al. Barriers to weight loss in obese patients with knee osteoarthritis. Ann R Coll Surg Engl 2010;92:338-40.

78 Holden MA, Nicholls EE, Young J, et al. Role of exercise for knee pain: what do older adults in the community think? Arthritis Care Res 2012;64:1554-64.

79 Basedow M, Runciman WB, March L, et al. Australians with osteoarthritis; the use of and beliefs about complementary and alternative medicines. Complement Ther Clin Pract 2014;20:237-42.

80 Lapane KL, Sands MR, Yang S, et al. Use of complementary and alternative medicine among patients with radiographic-confirmed knee osteoarthritis. Osteoarthritis Cartilage 2012;20:22-8.

81 Yang S, Dubé CE, Eaton CB, et al. Longitudinal use of complementary and alternative medicine among older adults with radiographic knee osteoarthritis. Clin Ther 2013;35:1690-702.

82 Gale J. HealthChange(TM) methodology: for patient-centred care and behaviour change support. Australia: HealthChange, 2014. www. healthchange.com
83 Harris PA, Taylor R, Thielke R, et al. Research electronic data capture (REDCap)-a metadata-driven methodology and workflow process for providing translational research informatics support. J Biomed Inform 2009;42:377-81.

84 Arthritis Research UK. Osteoarthritis of the knee 2027/OAK/13. Chesterfield, UK: Arthritis Research UK, 2013.

85 Bennell KL, Hinman RS. A review of the clinical evidence for exercise in osteoarthritis of the hip and knee. J Sci Med Sport 2011;14:4-9.

86 Hunter DJ, Hinman RS, Bowden JL, et al. Effectiveness of a new model of primary care management on knee pain and function in patients with knee osteoarthritis: protocol for the partner study. BMC Musculoskelet Disord 2018;19:132.

87 French SD, Green SE, O'Connor DA, et al. Developing theoryinformed behaviour change interventions to implement evidence into practice: a systematic approach using the theoretical domains framework. Implement Sci 2012;7:38

88 Grol R, Berwick DM, Wensing M. On the TRAIL of quality and safety in health care. BMJ 2008;336:74-6.

89 Davidoff F, Dixon-Woods M, Leviton L, et al. Demystifying theory and its use in improvement. BMJ Qual Saf 2015;24:228-38.

90 Basedow M, Williams H, Shanahan EM, et al. Australian GP management of osteoarthritis following the release of the RACGP guideline for the non-surgical management of hip and knee osteoarthritis. BMC Res Notes 2015;8:536.

91 Grimshaw JM, Thomas RE, MacLennan G, et al. Effectiveness and efficiency of guideline dissemination and implementation strategies. Health Technol Assess 2004;8:1-72.

92 De Silva MJ, Breuer E, Lee L, et al. Theory of change: a theory-driven approach to enhance the medical research council's framework for complex interventions. Trials 2014;15:267.

93 Smith SM, Soubhi H, Fortin M, et al. Interventions for improving outcomes in patients with multimorbidity in primary care and community settings. Cochrane Database Syst Rev 2012;4:CD006560.

94 Bowden JL, Egerton T, Hinman RS, et al. Protocol for the process and feasibility evaluations of a new model of primary care service delivery for managing pain and function in patients with knee osteoarthritis (partner) using a mixed methods approach. BMJ Open 2020;10:e034526. 